\title{
The Interaction of Amphotericin B Methyl Ester with Protoplasts of Candida albicans
}

\author{
By D. KERRIDGE, T. Y. KOH AND ALISON M. JOHNSON \\ Sub-department of Chemical Microbiology, Department of Biochemistry, \\ University of Cambridge, Cambridge $C B 2 \mathrm{I} Q W$
}

(Received 26 January 1976 ; revised 25 March 1976 )

SUMMARY

The interaction of amphotericin B methyl ester (AME) with protoplasts of Candida albicans was measured indirectly by following the incorporation of $\left[\mathrm{U}-{ }^{14} \mathrm{C}\right]$ phenylalanine into the acid-insoluble material. The inhibitory effects of AME at the minimum inhibitory concentration were prevented by the addition of $85 \mathrm{~mm}-\mathrm{KCl}$ and $45 \mathrm{~mm}-\mathrm{MgCl}_{2}$, as shown by Liras \& Lampen (1974) for Saccharomyces cerevisiae. In C. albicans, pretreatment of the yeast before antibiotic addition was unnecessary. $\mathrm{KCl}$ and $\mathrm{MgCl}_{2}$ did not prevent $\mathrm{AME}$ from binding to the protoplast membrane. This interaction was reversed by incubating the protoplasts in the presence of the protecting salts.

\section{INTRODUCTION}

The polyene antibiotics interact with sterol-containing membranes of sensitive cells causing leakage of cellular constituents and, ultimately, cell death (Lampen, I966 ; HamiltonMiller, 1974; Kerridge \& Russell, 1975). The fungicidal effects of certain members of this group of antibiotics can be prevented by the addition of $\mathrm{K}^{+}$and $\mathrm{Mg}^{2+}$ to the growth medium (Marini, Arnow \& Lampen, 196I ; Liras \& Lampen, 1974). It is assumed that the antibiotic interacts with the plasma membrane rendering it permeable to ions, but the presence of $\mathrm{K}^{+}$and $\mathrm{Mg}^{2}+$ ions in the suspending medium results in maintenance of the internal concentration required for growth. Polyene antibiotics have been used to affect reversibly the permeability of the plasma membrane of certain animal cells to both ions (Cass \& Dalmark, 1973) and DNA (Kumar et al., 1974). In these systems the antibiotic was removed simply by washing the cell suspension with the incubation medium. Amphotericin B, at sub-inhibitory concentrations, has also been used to potentiate the action of rifampicin in strains of yeast normally resistant to this compound (Kobayashi et al., I972).

The purpose of the studies reported in this paper was to investigate the effect of salts on the interaction of amphotericin B methyl ester (AME) with the plasma membrane of Candida albicans and on the reversibility of this interaction. There is considerable phenotypic variation in the sensitivity of $C$. albicans to AME when the organism is grown in batch culture (Gale, I974; Gale et al., 1975). For this reason protoplasts of C. albicans were used rather than intact cells, to eliminate possible interference by the cell wall with antibiotic penetration to the plasma membrane. In other studies on the interaction of polyene antibiotics with $C$. albicans, $\mathrm{K}^{+}$release has been used to monitor the interaction of the antibiotics with the membrane (Gale, 1974), but we could not use this procedure because of the need for high concentrations of $\mathrm{K}^{+}$in the external environment. The incorporation of a radioactively-labelled amino acid into the protein fraction was therefore used as an indirect measure of the functional integrity of the protoplast membrane. 


\section{METHODS}

Organisms and growth media. Candida albicans strain 6406, obtained from the Mycological Reference Laboratory, Public Health Laboratory Service, was used for these studies. The organism was maintained on Difco yeast morphology agar and, after growth at $37^{\circ} \mathrm{C}$, the cultures were stored at $4{ }^{\circ} \mathrm{C}$. For all experiments, the organism was grown at $37^{\circ} \mathrm{C}$ in an orbital incubator in the synthetic medium described by Davies (I953). Growth was determined by extinction and dry weight measurements.

Streptomyces violaceus 3196 was obtained from Professor J. R. Villanueva (Department of Microbiology, Salamanca University, Spain).

Protoplast formation. Suspensions of C. albicans were harvested during the exponential phase of growth when the culture density was $\mathrm{I} \mathrm{mg}$ dry $\mathrm{wt}^{\mathrm{ml}^{-1}}$. The yeast pellet was washed once with $0 . \mathrm{I} \mathrm{M}$-sorbitol, once with $0.8 \mathrm{M}$-sorbitol and finally resuspended at a density of $10 \mathrm{mg}$ dry wt $\mathrm{ml}^{-1}$ in $0 . \mathrm{I}_{\mathrm{M}}-\mathrm{NH}_{4} \mathrm{HCO}_{3}$ containing $0.8 \mathrm{M}$-sorbitol. Mercaptoethanol was added to a final concentration of $0.2 \mathrm{M}$ and the suspension was incubated at $37^{\circ} \mathrm{C}$ for $5 \mathrm{~min}$. The yeasts were harvested by centrifuging, washed once in $0.05 \mathrm{M}$-imidazole buffer $\mathrm{pH} 6.8$ containing $0.9 \mathrm{M}$-sorbitol and resuspended at a density of $10 \mathrm{mg}$ dry wt $\mathrm{ml}^{-1}$ in $0.05 \mathrm{M}$-imidazole buffer $\mathrm{pH} 6.8$ containing $\mathrm{r} \cdot 0 \mathrm{M}$ sorbitol and 'strepzyme' [prepared from Streptomyces violaceus 3196 as described by Elorza, Munoz-Ruiz \& Villanueva (1966)]. After $30 \mathrm{~min}$ incubation at $37^{\circ} \mathrm{C}$, bovine serum albumin (BSA) was added to a concentration of approximately $100 \mu \mathrm{g} \mathrm{ml}^{-1}$ and the incubation was continued until protoplast formation was complete (approx. 90 to $\mathrm{I} 20 \mathrm{~min}$ ). The 'strepzyme' preparation contained proteolytic enzymes which, although possibly important during the early stages of cell-wall lysis, could subsequently have affected the protoplast membrane proteins. The excess BSA was added during cell-wall removal to minimize this latter effect. The protoplasts were harvested by centrifuging for Io min at approx. $600 \mathrm{~g}$, washed once with $0.05 \mathrm{M}$-imidazole buffer $\mathrm{pH} 6.8$ containing $\mathrm{r} \cdot \mathrm{O} \mathrm{M}$-sorbitol and finally resuspended at a density equivalent to Io $\mathrm{mg}$ dry wt yeast $\mathrm{ml}^{-1}$ in the same buffer.

Incorporation of $\left[U_{-14} \mathrm{C}\right]$ phenylalanine into protoplasts. Protoplasts, at a density equivalent to I mg dry wt yeast $\mathrm{ml}^{-1}$ were incubated statically at $37^{\circ} \mathrm{C}$ in a medium containing: imidazole, $0.05 \mathrm{M}$; succinic acid, $0.05 \mathrm{M}$; sorbitol, $\mathrm{I} \cdot 0 \mathrm{M}$; Difco Casamino acids, $220 \mu \mathrm{g}$ $\mathrm{ml}^{-1}$; L-cysteine-HCl, L-tryptophan and L-phenylalanine, each at II $\mu \mathrm{g} \mathrm{ml}^{-1}$; [U-14 $\mathrm{C}$ ] phenylalanine (specific activity $495 \mathrm{mCi} \mathrm{mmol}^{-1}$ ), $0 \cdot 1 \mu \mathrm{Ci} \mathrm{ml}^{-1}$; other additions as required. Samples (I $\mathrm{ml}$ ) were withdrawn at intervals and pipetted into I $\mathrm{ml} 10 \%(\mathrm{w} / \mathrm{v})$ trichloroacetic acid (TCA). After I $5 \mathrm{~min}$ at $90{ }^{\circ} \mathrm{C}$ followed by $\mathrm{I} 5 \mathrm{~min}$ at $0{ }^{\circ} \mathrm{C}$, the precipitated protoplasts were harvested by filtration through glass-fibre filters, and washed with cold $5 \%(\mathrm{w} / \mathrm{v})$ TCA and $\mathrm{I} \%(\mathrm{v} / \mathrm{v})$ acetic acid. The filters were than transferred to small glass vials, dried at $105{ }^{\circ} \mathrm{C}$, I ml scintillant $[0.4 \%$ (w/v) 2,5-bis-(5-t-butylbenzoxazol-2-yl)thiophene (BBOT) in toluene] was added and the radioactivity was determined using a Packard model 3375 scintillation spectrometer.

Incubation of the protoplasts in the presence of glucose resulted in lysis during the course of the experiment, and succinate was used as the energy source for amino-acid uptake studies. The rate of phenylalanine incorporation into the acid-insoluble fraction was reduced at imidazole concentrations above $0.05 \mathrm{M}$, and was stimulated by $85 \mathrm{mM}-\mathrm{KCl}$ and $45 \mathrm{mM}-$ $\mathrm{MgCl}_{2}$ (Table I).

Materials. [U-14 C]Phenylalanine was obtained from The Radiochemical Centre, Amersham, Buckinghamshire. AME and filipin were a gift from Dr C. Schaffner, Department of Microbiology, Rutgers University, U.S.A. Trichodermin was a gift from Dr W. O. 
Table I. The effect of incubation conditions on the incorporation of $\left[U-{ }^{14} C\right]$ phenylalanine into protoplasts of Candida albicans

Protoplasts of Candida albicans were incubated at $37^{\circ} \mathrm{C}$ in the complete incorporation medium modified either by changing the concentration of imidazole or by adding salts, and the incorporation of $\left[\mathrm{U}-{ }^{14} \mathrm{C}\right]$ phenylalanine into the hot-TCA-insoluble material was measured.

Imidazole concn (M)

0.05

$0 \cdot \mathrm{I}$

0.2

0.05

0.05

0.05
Additions

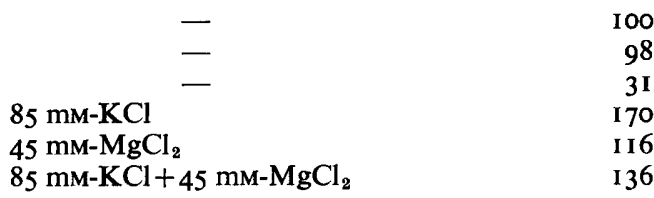
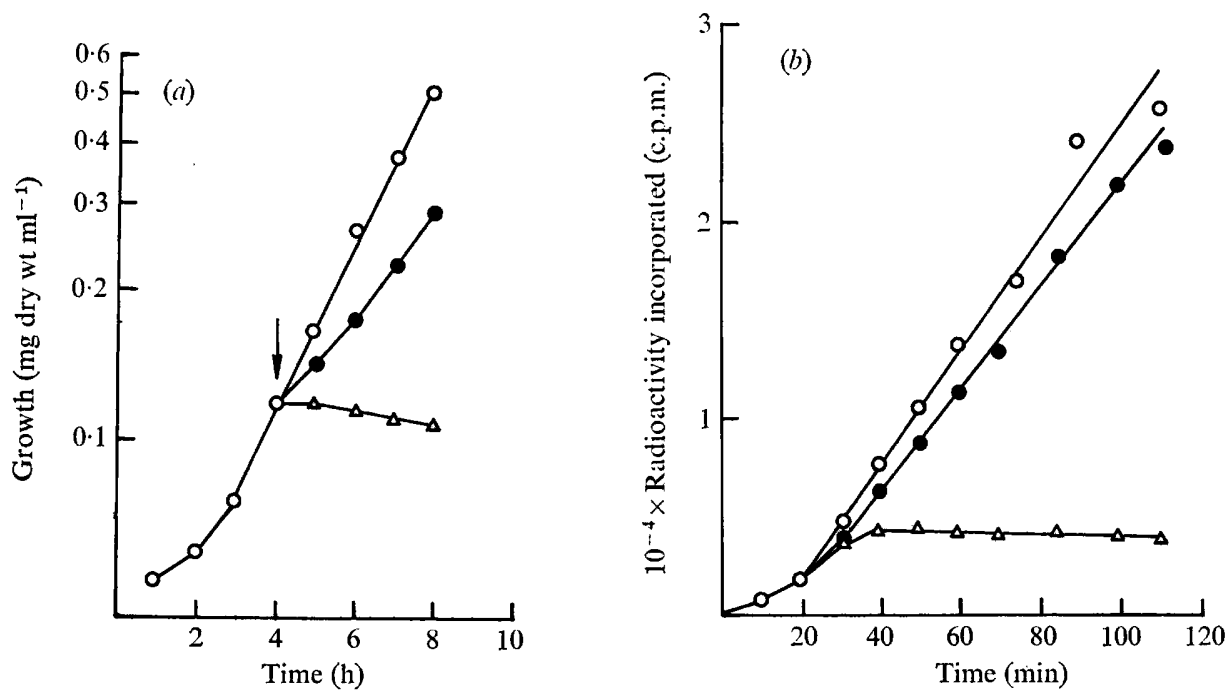

Fig. I. The effects of AME on the growth of $C$. albicans and on its incorporation of [U- $\left.{ }^{14} \mathrm{C}\right]$ phenylalanine. (a) A culture of $C$. albicans was incubated aerobically in synthetic yeast medium at $37^{\circ} \mathrm{C}$ and growth was determined spectrophotometrically. AME $\left(0 \cdot 1 \mu \mathrm{g} \mathrm{ml}^{-1}\right), 85 \mathrm{mM}-\mathrm{KCl}$ and 45 mM- $\mathrm{MgCl}_{2}$ were added as required when the culture was in the exponential phase of growth (at the time arrowed).

(b) A culture of $C$. albicans was incubated in the complete incorporation medium at $37^{\circ} \mathrm{C}$. $\operatorname{AME}\left(0 \cdot 1 \mu \mathrm{g} \mathrm{ml}^{-1}\right), 85 \mathrm{~mm}-\mathrm{KCl}$ and $45 \mathrm{mM}^{-} \mathrm{MgCl}_{2}$ were added as required after 10 min incubation, and the radioactivity of the hot $5 \%(\mathrm{w} / \mathrm{v}) \mathrm{TCA}$-insoluble material was determined.

$\bigcirc$, Control ; $\triangle$, AME added ; $, \mathrm{AME}, \mathrm{KCl}$ and $\mathrm{MgCl}_{2}$ added.

Godtfredsen, Leo Pharmaceutical Products, Denmark. All other chemicals were Analar grade, where possible.

\section{RESULTS}

Incorporation of $\left[U_{-14}{ }^{14}\right]$ phenylalanine into intact cells

The protective effects of $85 \mathrm{~mm}-\mathrm{KCl}$ and $45 \mathrm{~mm}-\mathrm{MgCl}_{2}$ observed by Liras \& Lampen (1974) for $S$. cerevisiae were also found with $C$. albicans. But in contrast to their findings, we were unable to demonstrate a requirement for pre-incubating the yeast in the presence of the salts before addition of AME to give complete protection (Fig. I). 


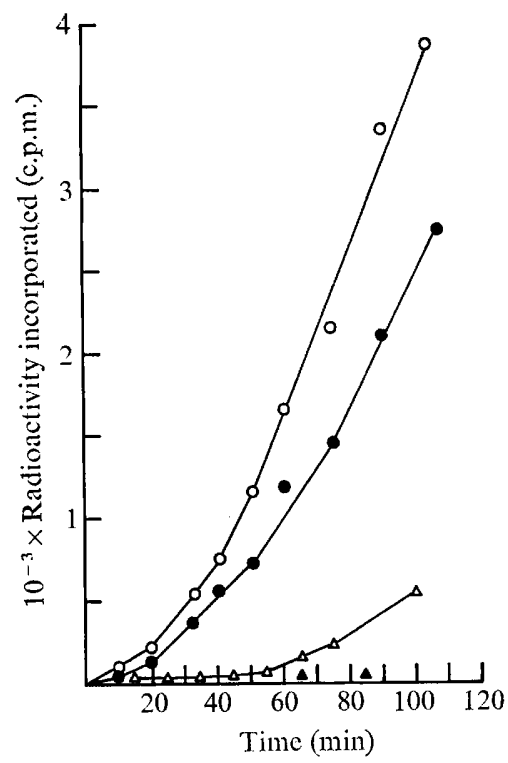

Fig. 2. The effect of $\mathrm{AME}$ in the presence of $\mathrm{KCl}$ and $\mathrm{MgCl}_{2}$ on $\left[\mathrm{U}-{ }^{14} \mathrm{C}\right]$ phenylalanine incorporation into protoplasts of $C$. albicans. Protoplasts were incubated in the incorporation medium; AME $\left(0 \cdot \mathrm{I} \mu \mathrm{g} \mathrm{ml}^{-1}\right), 85 \mathrm{mM}-\mathrm{KCl}$ and $45 \mathrm{mM}-\mathrm{MgCl}_{2}$ were added as required and the uptake of radioactivity into the hot $5 \%(\mathrm{w} / \mathrm{v}) \mathrm{TCA}$-insoluble material was determined. $\bigcirc$, Control, $\mathrm{KCl}$ and $\mathrm{MgCl}_{2}$ present throughout ; $\boldsymbol{\Lambda}, \mathrm{AME}$ present throughout; $\bullet, \mathrm{AME}$ present from time $0, \mathrm{KCl}$ and $\mathrm{MgCl}_{2}$ added after $2 \mathrm{~min} ; \triangle, \mathrm{AME}$ present from time $0, \mathrm{KCl}$ and $\mathrm{MgCl}_{2}$ added after $5 \mathrm{~min}$.

\section{Incorporation of $\left[U-{ }^{14} C\right]$ phenylalanine into protoplasts of $C$. albicans}

The incorporation of radioactivity from $\left[\mathrm{U}^{-14} \mathrm{C}\right]$ phenylalanine into the acid-insoluble residue by protoplast preparations provided a satisfactory, albeit indirect, measure of the integrity of the plasma membrane. Incorporation did not occur in lysed preparations, and it was completely inhibited by trichodermin (Io $\mu \mathrm{g} \mathrm{ml}^{-1}$ ), an inhibitor of protein synthesis (Cundliffe, Cannon \& Davies, I974), and by AME (0.1 $\mu \mathrm{g} \mathrm{ml}^{-1}$ ).

The inhibitory effect of AME, but not trichodermin, on the uptake of phenylalanine by intact protoplasts was completely reversed when $85 \mathrm{mM}-\mathrm{KCl}$ and $45 \mathrm{mM}-\mathrm{MgCl}_{2}$ were added to the incubation medium. Pre-incubation of the protoplasts with $\mathrm{KCl}$ and $\mathrm{MgCl}_{2}$ was not essential for this protection and, as in the case of intact cells, addition of the salts after AME was effective, and phenylalanine uptake occurred at almost the same rate as in the control (Fig. 2).

The protective effects of $\mathrm{KCl}$ and $\mathrm{MgCl}_{2}$ were not observed when AME was added at concentrations in excess of the minimum inhibitory concentration (m.i.c.). At concentrations of $\mathrm{I} \cdot 0 \mu \mathrm{g} \mathrm{ml}^{-1}$ and above, AME completely inhibited phenylalanine uptake both in the presence and absence of $\mathrm{KCl}$ and $\mathrm{MgCl}_{2}$. As with $S$. cerevisiae, neither salt alone protected the protoplasts against the inhibitory effects of AME.

\section{The association of AME with protoplast membranes in the presence of}

$$
\mathrm{K}^{+} \text {and } \mathrm{Mg}^{2+} \text { ions }
$$

Since we were unable to measure directly the binding of AME to protoplast membranes, we used an indirect approach to study the effects of salts on the interaction of AME with the plasma membrane and on the reversibility of this interaction. The protective effect of salts 


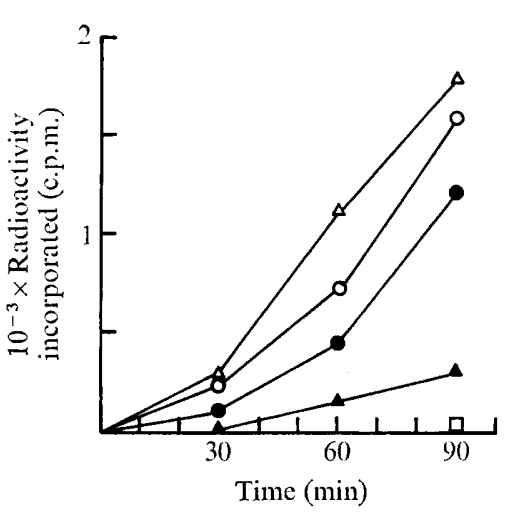

Fig. 3

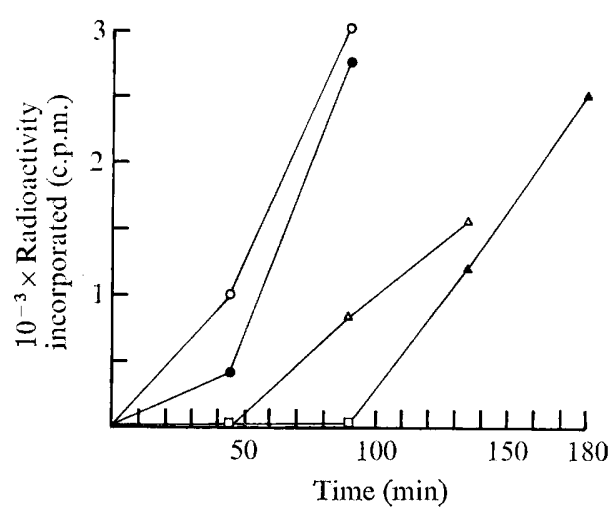

Fig. 4

Fig. 3. The effect of pre-incubation with AME on the synthetic ability of protoplasts of C. albicans. Protoplasts were incubated in the incorporation medium supplemented with $85 \mathrm{mM}-\mathrm{KCl}, 45 \mathrm{mM}-$ $\mathrm{MgCl}_{2}$ and $\mathrm{AME}\left(0 \cdot \mathrm{I} \mu \mathrm{g} \mathrm{ml}^{-1}\right.$ ) as required. After $\mathrm{I} 5 \mathrm{~min}$ incubation at $37^{\circ} \mathrm{C}$, they were harvested by centrifuging, resuspended in the incorporation medium in the presence or absence of protecting salts, and the incorporation of $\left[\mathrm{U}_{-}{ }^{14} \mathrm{C}\right]$ phenylalanine into the hot $5 \%(\mathrm{w} / \mathrm{v}) \mathrm{TCA}$-insoluble fraction was determined. $\bigcirc$, Control incubation, $\mathrm{KCl}$ and $\mathbf{M g C l}_{2}$ present throughout; $\triangle$, control incubation, $\mathrm{KCl}$ and $\mathrm{MgCl}_{2}$ present during pre-incubation only; $\bullet, \mathrm{KCl}$ and $\mathrm{MgCl}_{2}$ present throughout, AME present during first incubation only; $\mathbf{\Delta}, \mathbf{K C l}, \mathrm{MgCl}_{2}$ and $\mathrm{AME}$ present during first incubation only; $\square$, lysed control.

Fig. 4. Recovery of synthetic ability by protoplasts of $C$. albicans after treatment with AME. Protoplasts were incubated in the incorporation medium supplemented with $85 \mathrm{mM}-\mathrm{KCl}, 45 \mathrm{mM}-\mathrm{MgCl}_{2}$ and $\operatorname{AME}\left(0 \cdot 1 \mu \mathrm{g} \mathrm{ml}^{-1}\right)$ as required. After $15 \mathrm{~min}$ incubation at $37^{\circ} \mathrm{C}$, they were harvested by centrifuging and resuspended in the incorporation medium supplemented with $85 \mathrm{mM}-\mathrm{KCl}$ and $45 \mathrm{mM}^{-\mathrm{MgCl}_{2}}$. After a further 0,45 and 90 min incubation at $37^{\circ} \mathrm{C}$, samples were withdrawn, protoplasts were harvested by centrifuging and resuspended in the incorporation medium, and the incorporation of $\left[\mathrm{U}_{-}{ }^{14} \mathrm{C}\right]$ phenylalanine into the hot $5 \%(\mathrm{w} / \mathrm{v}) \mathrm{TCA}$-insoluble fraction was determined. $\mathrm{O}$, Control, $\mathrm{KCl}$ and $\mathrm{MgCl}_{2}$ present throughout ;, $\mathrm{KCl}$ and $\mathrm{MgCl}_{2}$ present throughout, AME present during first incubation only; $\square, \mathrm{KCl}, \mathrm{MgCl}_{2}$ and $\mathrm{AME}$ present during the first incubation only ; $\triangle, \mathrm{KCl}, \mathrm{MgCl}_{2}$ and $\mathrm{AME}$ present during the first incubation, after 45 min incubation in the incorporation medium supplemented with $\mathrm{KCl}$ and $\mathrm{MgCl}_{2}$, the incorporation of phenylalanine by protoplasts was followed in the absence of protecting salts ; $\mathbf{\Delta}, \mathrm{KCl}, \mathrm{MgCl}_{2}$ and $\mathrm{AME}$ present during the first incubation, after 90 min incubation in the incorporation medium supplemented with $\mathrm{KCl}$ and $\mathrm{MgCl}_{2}$, the incorporation of phenylalanine by protoplasts was followed in the absence of protecting salts.

could result either from preventing the antibiotic from binding, possibly by precipitating the $\mathrm{AME}$, or from the high concentrations of salts maintaining the necessary internal concentrations of $\mathrm{K}^{+}$and $\mathrm{Mg}^{2}+$ ions. If the former, phenylalanine incorporation should take place once the excess antibiotic and salts were removed; whereas if the latter were the cause, uptake should cease once the antibiotic and salts were removed if membrane damage had been sustained in the presence of the salts. This was investigated by incubating protoplast suspensions in the presence of AME together with the protecting salts. After I5 min incubation at $37^{\circ} \mathrm{C}$, the protoplasts were harvested by centrifuging and resuspended in the incorporation medium in the presence or absence of the protecting salts, and the synthetic abilities of the protoplasts were measured. The results of such an experiment are shown in Fig. 3. Radioactive phenylalanine was only incorporated when the protecting salts were present in the incubation medium. This would suggest that AME was bound to the membrane in the presence of $\mathrm{K}^{+}$and $\mathrm{Mg}^{2+}$, but once these ions together with any free AME were 
removed from the suspending medium, leakage of internal constituents occurred, resulting in the loss of synthetic ability by the protoplasts.

The association of amphotericin B with both animal cells (Cass \& Dalmark, I973; Kumar et al., 1974) and mycoplasma cell membrane (D. B. Archer, University of Cambridge, personal communication) is reversible, and so we investigated the possibility that the binding of AME to protoplast membranes was also reversible. A suspension of protoplasts was incubated with $\mathrm{AME}$ at its m.i.c. together with $85 \mathrm{mM}-\mathrm{KCl}$ and $45 \mathrm{mM}-\mathrm{MgCl}_{2}$. After $30 \mathrm{~min}$ incubation, the protoplasts were harvested and resuspended in the incubation medium lacking $\left[\mathrm{U}-{ }^{14} \mathrm{C}\right]$ phenylalanine but containing the protecting salts. Samples were removed at intervals, protoplasts harvested and resuspended in the normal incorporation medium and the uptake of phenylalanine into the acid-insoluble residue was measured. Initially the protoplasts were unable to incorporate phenylalanine when resuspended in the absence of $\mathrm{KCl}$ and $\mathrm{MgCl}_{2}$; but there was a progressive recovery of synthetic activity, presumably due to the release of AME from the plasma membrane, and after 90 min the protoplasts had completely regained their synthetic ability (Fig. 4). The addition of trichodermin had no effect on the recovery of synthetic ability under these conditions.

\section{The effect of filipin on the incorporation of phenylalanine into protoplasts of C. albicans}

The presence of $\mathrm{K}^{+}$and $\mathrm{Mg}^{2+}$ does not protect $S$. cerevisiae against the action of the polyene antibiotic filipin (Liras \& Lampen, 1974). We confirmed these findings with protoplasts of $C$. albicans. The incorporation of $\left[\mathrm{U}-{ }^{14} \mathrm{C}\right]$ phenylalanine into $C$. albicans incubated in the presence of AME, $85 \mathrm{mM}-\mathrm{KCl}$ and $45 \mathrm{mM}-\mathrm{MgCl}_{2}$ was completely inhibited by adding filipin at $10 \mu \mathrm{g} \mathrm{ml}^{-1}$. Thus, under these conditions, the association of AME with components of the plasma membrane did not prevent the subsequent disruption of the membrane by filipin.

\section{DISCUSSION}

It is generally agreed that AME interacts with sterols present in the plasma membrane of sensitive cells, resulting in the formation of pores through which low-molecular-weight constituents of the cell can pass, and that it is this loss of cellular constituents which is ultimately responsible for loss of viability (Hamilton-Miller, 1974). The prevention of the fungicidal action of certain of the polyene antibiotics by addition of potassium and magnesium ions to the suspending medium has been explained by the role of these ions in maintaining the internal concentration within the cell. The finding that this protection did not occur when the polyene antibiotic AME was present at concentrations in excess of the m.i.c. would suggest that the increased damage to the protoplast membrane cannot be compensated for by environmental changes, and emphasizes the importance of studying the effect of an antibiotic over a range of concentrations. Although $\mathrm{K}^{+}$and $\mathrm{Mg}^{2+}$ ions protected protoplasts of $C$. albicans against the action of AME, they did not prevent the antibiotic from binding to the plasma membrane impairing membrane function. The binding of AME to the protoplast membrane could be reversed, with recovery of membrane function, provided the protecting salts were present during this period. The fungicidal effects of the polyene antibiotics therefore result from the irreversible damage to the cell caused by leakage of cellular constituents rather than the irreversible binding of the antibiotic to the plasma membrane. It is unlikely that the protective effects of salts and the reversibility of the polyene binding to the yeast plasma membrane are important in the treatment of clinical infections since both require the presence of $\mathrm{K}^{+}$and $\mathrm{Mg}^{2}+$ at high concentrations. However the 
reversibility of the effects of the polyenes on animal cells in the absence of protecting ions might be important in minimizing the damaging effects of the antibiotic on the host's cells during treatment of systemic fungal infections.

The authors wish to thank the Medical Research Council for financial support and their colleagues for their continued interest in these studies.

\section{REFERENCES}

Cass, A. \& Dalmark, M. (1973). Equilibrium dialysis of ions in nystatin-treated red cells. Nature, London 244, 47-49.

Cundliffe, E., Cannon, M. \& Davies, J. (1974). Mechanism of inhibition of eukaryotic protein synthesis by trichothecene fungal toxins. Proceedings of the National Academy of Science of the United States of America 7x, 30-34.

Davies, R. (1953). Enzyme formation in Saccharomyces fragilis. I. Invertase and raffinase. Biochemical Journal 55, 484-497.

Elorza, M. V., Munoz-Ruiz, E. \& Villanueva, J. R. (I966). Production of yeast cell wall lytic enzymes on a semi-defined medium by a Streptomyces. Nature, London 210, 442-443.

Gale, E. F. (1974). The release of potassium ions from Candida albicans in the presence of polyene antibiotics. Journal of General Microbiology 8o, $45 \mathrm{I}-465$.

Gale, E. F., Johnson, A. M., KerRidge, D. \& KoH, T. Y. (1975). Factors affecting the changes in amphotericin sensitivity of Candida albicans during growth. Journal of General Microbiology 87, 20-36.

Hamilton-Miller, J. M. T. (1974). Chemistry and biology of the polyene macrolide antibiotics. Bacteriological Reviews 37, I66-I96.

KerRIDGe, D. \& Russell, N.J. (1975). Polyenes : actions and prospects. In Chemotherapy Progress, vol. 6 , Proceedings of the Sixth International Congress of Chemotherapy, pp. III-II6. New York and London: Plenum Publishing Corp.

Kobayashi, G. S., Medoff, G., Schlessinger, D., Kwan, G. N. \& Musser, W. E. (1972). Amphotericin B potentiation of rifampicin as an antifungal agent against the yeast phase of Histoplasma capsulatum. Science, New York I77, 709-710.

Kumar, B. V., Medoff, G., Kobayashi, G. S. \& Schlessinger, D. (I974). Uptake of Escherichia coli DNA into HeLa cells enhanced by amphotericin B. Nature, London 256, 323-325.

LAMPEN, J. O. (I966). Interference by polyene antifungal antibiotics (especially nystatin and filipin) with specific membrane functions. Symposia of the Society for General Microbiology 16, I I I-I 30.

Liras, P. \& LAMPEN, J. O. (1974). Protection by $\mathrm{K}^{+}$and $\mathrm{Mg}^{++}$of growth and macromolecular synthesis in candicidin treated yeast. Biochimica et biophysica acta 374, 159-163.

Marini, F., ARnow, P. \& LAMPEn, J. O. (I96I). The effect of monovalent cations on the inhibition of yeast metabolism by nystatin. Journal of General Microbiology 24, 5I-62. 